\title{
Management Responses to Negative Online Customer Reviews: The Effect of Compensation and Explanation on the Observer's Purchase Intention: An Abstract
}

\author{
Rico Piehler, Michael Schade, Ines Nee, and Christoph Burmann
}

\begin{abstract}
Negative online customer reviews affect potential customers' purchase decisions. Observers represent potential customers who read online customer reviews to make informed purchase decisions. Consequently, there is a need to respond to negative online customer reviews. This study investigates the effect of compensation and explanation on observer's purchase intention. Applying an experimental between-subjects design, the results of a study with 381 participants show that a monetary compensation combined with an explanation has the greatest effect on the observer's purchase intention. More importantly, a monetary compensation and an explanation alone each have the same positive effect on the observer's purchase intention. As compensating monetarily implies significant financial losses, organizations are advised to provide an explanation in cases of resource constraints.
\end{abstract}

References Available Upon Request

R. Piehler $(\bowtie) \bullet$ M. Schade $\bullet$ I. Nee $\bullet$ C. Burmann

University of Bremen, Bremen, Germany

e-mail: rico.piehler@uni-bremen.de; mschade@uni-bremen.de; limsekr@uni-bremen.de;

burmann@uni-bremen.de 